\title{
GENETIC ARCHITECTURE OF NUMBERS OF FAST AND SLOW MUSCLE FIBRES IN THE MOUSE SOLEUS MUSCLE
}

\author{
W. J. VAN DER LAARSE,* W. E. CRUSIO, $\dagger$, SUHARTI MASLAM* \\ AND J. H. F. VAN ABEELEN'
}

*University of Amsterdam, Department of Zoology, Kruislaan 320, 1098 SM Amsterdam, The Netherlands; † University of Nijmegen, Department of Zoology, Toernooiveld, 6525 ED Nijmegen, The Netherlands.

Received 24.iv.84

\section{SUMMARY}

\begin{abstract}
This report analyses the genetic architecture underlying a muscle fibre characteristic. We have counted numbers of fast and slow muscle fibres in the soleus muscle of male mice from different inbred strains and crosses between them (diallel cross). Broad heritabilities of 20 per cent and 73 per cent were found for the number of slow fibres and the number of fast fibres, respectively. Additive genetic variation was present for both phenotypes. Directional dominance was found for number of fast fibres only. This suggests that, in evolutionary history, stabilising selection has operated for intermediate numbers of slow muscle fibres and directional selection for high numbers of fast fibres.
\end{abstract}

\section{INTRODUCTION}

The histochemical and physiological characteristics of mammalian skeletal muscle fibres range widely (Close, 1972; Kahn, 1976; Burke, 1978). Fast and slow fibre types can be distinguished by means of myofibrillar ATPase histochemistry. Fast muscle fibres have relatively high, alkali stable, myofibrillar ATPase activities and are maximally efficient at high shortening speeds, while slow muscle fibres have relatively low, alkali labile, myofibrillar ATPase activities and are maximally efficient at low shortening speeds (Kahn, 1976; Goldspink, 1977). These fibre types are probably specialised in performing their function.

Exactly how the muscle fibre differentiation is accomplished is unknown. The maximal intrinsic shortening speeds of developing fast and slow muscles are approximately equal in early postnatal stages. In the first period of life, the intrinsic shortening speed of the incipient fast muscle increases about twofold (Close, 1972). This change coincides with changes in myofibrillar proteins (Pool, 1980; Rubinstein and Kelly, 1981). Cross-innervation and chronic stimulation experiments in adult mammals suggest that the innervation determines muscle fibre differentiation (for a review, see Edgerton, 1978). This does not imply, however, that the innervation determines muscle fibre differentiation in myogenesis. In 1974, Vaughan et al., demonstrated differences between the percentages of alkali labile ATPase muscle fibres of the mouse soleus muscle in different strains. They suggested that muscle fibre differentiation is determined genetically.

In order to establish the role played by genetic factors in the muscle fibre differentiation in this muscle, we have analysed the genetic architectures of the number of fast fibres $\left(N_{f}\right)$ and the number of slow fibres $\left(N_{s}\right)$. 


\section{MATERIALS AND METHODS}

We have determined the muscle fibre composition of the soleus muscle in the highly inbred mouse strains $\mathrm{C} 57 \mathrm{BL} / 6 \mathrm{~J} / / \mathrm{Nmg}(B), \mathrm{DBA} / 2 \mathrm{~J} / / \mathrm{Nmg}$ (D), $\mathrm{C} 3 \mathrm{H} / \mathrm{St} / \mathrm{Nmg}(\mathrm{H})$, and $\mathrm{CPB}-\mathrm{K} / / \mathrm{Nmg}(\mathrm{K})$, and all possible $\mathrm{F}_{1}$ crosses between them, including reciprocals. One (hybrids) or two (inbreds) litters were raised, from which one male mouse was analysed at 3-4 months of age. All litters were second litters, and all animals were fostered to a random-bred strain. This design was replicated four times (four blocks) so that a total of 80 mice was used.

The numbers of fast and slow muscle fibres were determined from a cross section of the muscle between the tendons, stained for myofibrillar ATPase (van der Laarse et al., 1984).

The quantitative-genetic methods described by Hayman (1954) and by Mather and Jinks (1982) were modified because of the double number of inbreds in the leading diagonal of the dialled table (see Jones, 1965). The complete method has been described by Crusio et al., (1984).

\section{Results}

Table 1 shows mean numbers of fast and slow extrafusal muscle fibres in the soleus muscle of the 16 different genotypes. The raw data were transformed in order to obtain homogeneous variances in the genetic groups

TABLE 1

Diallel table of mean numbers $\pm S E M$ of fast and slow muscle fibres in the soleus muscle of mice

\begin{tabular}{|c|c|c|c|c|c|}
\hline$\delta$ & B & D & $\mathbf{H}$ & $\mathbf{K}$ & Fibre type \\
\hline B & $\begin{array}{l}549 \pm 23 \cdot 2 \\
328 \pm 17 \cdot 3\end{array}$ & $\begin{array}{l}518 \pm 15 \cdot 4 \\
294 \pm 18 \cdot 2\end{array}$ & $\begin{array}{l}465 \pm 53 \cdot 5 \\
273 \pm 17.9\end{array}$ & $\begin{array}{l}399 \pm 33 \cdot 5 \\
279 \pm 42 \cdot 1\end{array}$ & $\begin{array}{l}\text { fast } \\
\text { slow }\end{array}$ \\
\hline D & $\begin{array}{l}553 \pm 14 \cdot 6 \\
324 \pm 17 \cdot 6\end{array}$ & $\begin{array}{l}445 \pm 26 \cdot 9 \\
340 \pm 13 \cdot 7\end{array}$ & $\begin{array}{l}447 \pm 22 \cdot 4 \\
322 \pm 16 \cdot 2\end{array}$ & $\begin{array}{l}339 \pm 18 \cdot 1 \\
311 \pm 17 \cdot 7\end{array}$ & $\begin{array}{l}\text { fast } \\
\text { slow }\end{array}$ \\
\hline $\mathbf{H}$ & $\begin{array}{l}525 \pm 25 \cdot 9 \\
294 \pm 21 \cdot 7\end{array}$ & $\begin{array}{l}411 \pm 22 \cdot 8 \\
311 \pm 13 \cdot 6\end{array}$ & $\begin{array}{l}316 \pm 14.6 \\
259 \pm 12.8\end{array}$ & $\begin{array}{l}292 \pm 15 \cdot 2 \\
268 \pm 23 \cdot 0\end{array}$ & $\begin{array}{l}\text { fast } \\
\text { slow }\end{array}$ \\
\hline $\mathbf{K}$ & $\begin{array}{l}465 \pm 7 \cdot 1 \\
315 \pm 18 \cdot 9\end{array}$ & $\begin{array}{l}320 \pm 11 \cdot 2 \\
339 \pm 14 \cdot 4\end{array}$ & $\begin{array}{l}277 \pm 20 \cdot 8 \\
248 \pm 27 \cdot 5\end{array}$ & $\begin{array}{l}187 \pm 10 \cdot 9 \\
259 \pm 20 \cdot 3\end{array}$ & $\begin{array}{l}\text { fast } \\
\text { slow }\end{array}$ \\
\hline
\end{tabular}

Inbreds: $n=8$, hybrids: $n=4$.

(so-called cells) and normality of distribution (Sachs, 1974). Table 2 shows these transformations and the results of the Hayman analyses. The betweencell variance was significant for both phenotypes. The $b$ item indicated dominance for phenotype $N_{f}$ only. This dominance was directional, judging from the significant $b_{1}$ item. Other forms of dominance ( $b_{2}$ and $b_{3}$ items) and reciprocal differences ( $c$ and $d$ items) were not found. In view of the nonsignificance of $b_{2}$ and $b_{3}$, the significant $a$ items are taken to indicate additive genetic variation (see, for discussion, Crusio et al., 1984). There were no significant differences between blocks.

The assumptions on which the Hayman analysis is based (relevant here are: no epistatic interactions, no multiple allelism, and independent distribu- 
TABLE 2

Hayman analyses and joint regression analyses of $\mathrm{W}_{\mathrm{r}}$ on $\mathrm{V}_{\mathrm{r}}$

\begin{tabular}{|c|c|c|c|}
\hline $\begin{array}{l}\text { Phenotype* } \\
\text { Transformation }\end{array}$ & & $\begin{array}{l}N_{f} \\
\sqrt[3]{x}\end{array}$ & $\begin{array}{l}N_{s} \\
x^{2}\end{array}$ \\
\hline \multicolumn{4}{|l|}{ Hayman ANOVA } \\
\hline Item & $\mathrm{df} \dagger$ & $F \ddagger$ & $F$ \\
\hline$a$ & 3,9 & $361 \cdot 75^{* * *}$ & $5 \cdot 55^{*}$ \\
\hline$b$ & 6,18 & $3 \cdot 72^{*}$ & 0.97 \\
\hline$b_{1}$ & 1,3 & $67 \cdot 28^{* *}$ & 0.00 \\
\hline$b_{2}$ & 2,6 & 0.43 & $1 \cdot 00$ \\
\hline$b_{3}$ & 3,9 & 4.66 & $2 \cdot 49$ \\
\hline$c$ & 3,9 & $2 \cdot 18$ & 0.77 \\
\hline$d$ & 3,9 & 1.56 & $1 \cdot 16$ \\
\hline Between-cell & 15,61 & $30 \cdot 20^{* * *}$ & $2 \cdot 45^{* *}$ \\
\hline Blocks & 3,61 & 2.43 & 0.96 \\
\hline \multicolumn{4}{|c|}{ Joint regression of $W_{r}$ on $V_{r}$} \\
\hline Item & $\mathrm{df}$ & $F$ & $F$ \\
\hline Joint regression & 1,3 & $1756^{* * *}$ & $85 \cdot 43^{* * *}$ \\
\hline Heterogeneity & 3,11 & $0 \cdot 14$ & $1 \cdot 15$ \\
\hline
\end{tabular}

* $N_{f}$, number of fast fibres; $N_{s}$ number of slow fibres.

$\dagger$ df, degrees of freedom; each item was tested against its own block interaction.

$\ddagger^{*} P<0.05,{ }^{* *} P<0.01,{ }^{* * *} P<0.001$.

tion of alleles among parents) were tested in the variance-covariance analysis. The ANOVA of the sums of the array variances $\left(V_{r}\right)$ and the array covariances of hybrids with their non-recurrent parents $\left(W_{r}\right)$ showed significant differences between arrays for $N_{f}$, indicating that dominance is present. Further, $V_{r}+W_{r}$ was negatively correlated with the parental phenotypes for $N_{f} ; r_{s}=-0.78, \mathrm{df}=14, P<0.001$ (Spearman rank correlattion coefficient; Siegel, 1956), confirming the directional dominance for high number of fast fibres suggested by the Hayman analysis. The ANOVA of $V_{r}-W_{r}$ detected no differences between arrays. The joint regression analyses of $W_{r}$ on $V_{r}$ showed, for both phenotypes, that a linear relationship exists between $W_{r}$ and $V_{r}$ which is homogeneous over blocks (table 2). The slopes of the regression lines do not differ significantly from unity (slope \pm S.E.: $0.97 \pm 0.06, t_{11}=0.48 ; 0.98 \pm 0.10, t_{11}=0.20$, for $N_{f}$ and $N_{s}$, respectively). This is a requirement for the Hayman analysis. The intercepts of the regression lines measure $\left(D-H_{1}\right) / 4$, where parameter $D$ estimates additive genetic variance, and parameter $H_{1}$ estimates the variance due to dominance variations. The intercepts, corrected for environmental variation, are different from zero $\left(N_{f}: z=8.88, P<0.001, N_{s}: z=1.98, P<0.05\right)$, indicating that the dominance for $N_{f}$ is incomplete.

Table 3 shows the estimates of the genetic parameters. Parameter $\sqrt{H_{1} / D}$ estimates the degree of dominance. It is significantly larger than zero for $N_{f}$. Large narrow and broad heritabilities, $h_{(n)}^{2}$ and $h_{(b)}^{2}$, respectively, were found for $N_{f}$ indicating that genetic factors are relatively important in determining this phenotype. The narrow and broad heritabilities for $N_{s}$ are 
TABLE 3

Estimates of the most important genetic parameters

\begin{tabular}{ccc}
\hline $\begin{array}{c}\text { Phenotype* } \\
\text { Parameter }\end{array}$ & $N_{f}$ & $N_{s}$ \\
\hline$\sqrt{H_{1} / D}$ & 0.34 & 0.00 \\
$h_{(n)}^{2}$ & 0.69 & 0.20 \\
$h_{(b)}^{2}$ & 0.73 & 0.20 \\
$k$ & 2.00 & 0.00 \\
\hline
\end{tabular}

* $N_{f}$, number of fast fibres; $N_{s}$, number of slow fibres.

equal because there is no dominance and they are also much smaller. Dominance is directional for $N_{f}$ so that a minimum estimate of the number $(k)$ of effective genetic factors showing dominance can be calculated. A polygenic system is probably involved.

\section{Discussion}

We conclude that the genetic architectures of the numbers of fast and slow fibres differ. Only additive genetic variation was found for the number of slow muscle fibres, whereas directional dominance was present for high numbers of fast fibres. These findings permit two important conclusions. First, the regulatory systems for the number of fast and slow muscle fibres differ, at least in part. Second, in the evolutionary past, different kinds of selection have operated on these phenotypes. Assuming that we have sampled randomly from the genepool, we may conclude that, in phylogeny, stabilising selection has occurred for the number of slow fibres and a small amount of directional selection for high numbers of fast fibres.

Acknowledgements. We thank Anton Buis and Ron Engels for their skillful biotechnical assistance. This study was supported, in part, by a grant from the Netherlands Foundation for Biological Research (BION), with financial aid from the Netherlands Organisation for the Advancement of Pure Research (ZWO).

\section{REFERENCES}

BURKE, R. E. 1978. Motorunits: physiological histochemical profiles, neuronal connectivity and functional specialization. Am. Zool, 18, 127-134.

CLOSE, R. I. 1972. Dynamic properties of mammalian skeletal muscle fibres. Physiol. Rev., 52, 129-147.

CRUSIO, W. E., KERBUSCH, J. M. L. AND ABEELEN. J. H. F. VAN, 1984. The replicated diallel cross; a generalized method of analysis. Behav. Genet, 14, 81-104.

EDGERTON, V. R. 1978. Mammalian muscle fibre types and their adaptability. Am. Zool., 18, 113-125.

GOLDSPINK. G. 1977. Muscle energetics and animal locomotion. In: Alexander, RMcN, Goldspink, G. (eds.) Mechanics and Energetics of Animal Locomotion, Chapman and Hall, London.

HAYMAN, B. I. 1954. The analysis of variance of diallel tables. Biometrics, 10, 235-244.

JONES, R. M. 1965. Analysis of variance of the half diallel table. Heredity, 20, 117-121.

KAHN, M. A. 1976. Histochemical characteristics of vertebrate striated muscle: a review. Progr. Histochem. Cytochem., 8(4), 1-48. 


\section{GENETIC ARCHITECTURE OF NUMBERS OF MUSCLE FIBRES 647}

LAARSE, W. J. VAN DER, DIEGENBACH, P. C. AND SUHARTI MASLAM, 1984. Quantitative histochemistry of three mouse hindlimb muscles: the relationship between calcium stimulated myofibrillar ATPase and succinate dehydrogenase activities. Histochem. J., 16, 529-541.

MATHER, K. AND JINKS, J. L. 1982. Biometrical Genetics (3rd ed). Chapman and Hall, London. POOL, C. W. 1980. An immune- and enzyme histochemical determination of striated muscle fibre characteristics. Thesis, University of Amsterdam.

RUBINSTEIN, N. A. AND KELLY, A. M. 1981. Development of muscle fibre specialization in the rat hindlimb. J. Cell Biol., 90, 128-144.

SACHS, L. 1974. Angewandte Statistik, Springer Verlag, Berlin.

SIEGEL, S. 1956. Non-parametric statistics for the behavioral sciences. McGraw-Hill, New York. VAUGHAN, H. S., AZIZ-Ullah, GOldsPiNK, G. AND NOWEll, N. W. 1974. Sex and stock differences in the histochemical myofibrillar adenosine triphosphatase reaction in the soleus muscle of the mouse. J. Histochem. Cytochem., 22, 155-159. 